Hispania Sacra, LX

121, enero-junio 2008, 143-171, ISSN: 0018-215-X

\title{
LA VIDA INTELECTUAL EN LOS MONASTERIOS CISTERCIENSES NAVARROS. LA ESCUELA DE GRAMÁTICA Y BIBLIOTECA DEL MONASTERIO DE IRANZU EN EL S. XVI
}

POR

$\mathrm{M}^{\mathrm{a}}$ Isabel Ostolaza Elizondo

Universidad Pública de Navarra

\section{RESUMEN}

El descubrimiento y análisis del inventario de la biblioteca del monasterio cisterciense de Iranzu a fines del s. XVI, da pie al estudio de la escuela de gramática de este monasterio en la etapa Humanística, así como al diagnostico del nivel intelectual de los monasterios cistercienses navarros en los momentos en que $\mathrm{Fe}$ lipe II trata de ponerlos bajo la autoridad de Castilla. Se deduce que los argumentos esgrimidos por los informadores del rey sobre las deficiencias intelectuales de sus abades, son una excusa para justificar los verdaderos intereses regios, que no eran sino los de sustraer dichos centros de la obediencia de la casa madre francesa, por temor a las influencias heréticas que pudieran llegar de un pais en plena guerra de religión. Finalmente los planes filipinos saldrán adelante utilizando como arma contundente el Derecho de Patronato, aunque en el s. XVII los monasterios ciscercienses navarros conseguirán incardinarse jerarquicamente con la provincia de Aragón y no de Castilla.

PALABRAS CLAVE: Escuela de gramática de Iranzu, Biblioteca del monasterio de Iranzu,Estudios Humanísticos en Iranzu, Formación intelectual en los monasterios cistercienses navarros.

\section{ABSTRACT}

The discovery and analysis of the inventory of the library of the cisterciense monastery of Iranzu by the end of s. XVI, gives foot to the study of the school of grammar of this monastery in the humanistic stage, as well as to a diagnose of the intellectual level of the Navarrese cistercienses monasteries at the moments at which Felipe II tries to put them under the authority of Castile. It is deduced that the arguments used by the informers of the king on the intellectual deficiencies of 
its abbots, are an excuse to justify the true regal interests, that were not but those to remove to these centers of the obedience of the house French mother, from fear of the heretical influences that could arrive at the heat of a country that was living a religion war process. Finally the philippine plans will leave ahead using like blunt weapon the Right Patronage, although in s. XVII the Navarrese ciscercienses monasteries will be able to narrow a union of themselves hierarchically with the province of Aragón and not of Castile.

KEY WORDS: School of grammar of Iranzu, Library of the monastery of Iranzu, Humanistic studies in Iranzu, Intellectual formation in the Navarrese cistercienses monasteries

Recibido/Received 23-01-2007

Aceptado/Accepted 25-06-2007

La llegada de la Orden cisterciense a Navarra, supuso la creación de nuevos monasterios como los de Fitero (1140), la Oliva (1151), Iranzu (1176), Sales (1266). El progreso del Císter sobre otras órdenes monásticas se aprecia a lo largo del s. XIII en el que debido a la relajación de los benedictinos, la autoridad episcopal y pontifícia propiciaron tras largos pleitos, la instalación del Císter en Leire, que pasó a depender jerárquicamente del monasterio de Scala Dei en la diócesis de Tarbes ${ }^{1}$. El estilo de vida de la Orden fundada por S. Bernardo de Claraval era mucho más sencillo que el de la Orden de Cluny, por lo que tanto la arquitectura como las celebraciones religiosas se vieron imbuidas de esa austeridad, resaltando la vida espiritual sobre todo tipo de distracciones superfluas. El Císter que no estaba ajeno a las necesidades materiales de supervivencia de sus frailes, potenció en cada monasterio la autonomía tanto en lo referente al sustento del cuerpo, (de ahí el enorme desarrollo de la agricultura y la ganadería en las granjas anexas a los centros monásticos), como del alma (el trabajo de sus scriptoria, a fin de proporcionar los libros necesarios para la liturgia y la lectura espiritual de los monjes, con formas de representación alejadas de toda ostentación que han dado lugar a lo que se conoce como estilo cisterciense).

Por ello la Orden inspiró y apoyó la formación intelectual de sus monjes, y lo hizo en Navarra creando un Estudio General para los monasterios cistercienses del Reino, que tuvo su sede en Estella desde el año 1289 al 1335, en que Benedicto XII determinó que el Estudio se trasladara a Salamanca ${ }^{2}$. Sin embargo algunos de los monasterios cistercienses navarros no renunciaron a las tareas de formación intelectual, en aras a convertirse de esta forma en semillero de vocaciones religiosas, abriendo sus conventos a los hijos las familias del entorno,

${ }^{1}$ L. J. Fortún PÉREZ de CIRIZA, Leire. Un señorío monástico en Navarra (s. IX-XIX). Pamplona: Gobierno de Navarra, Dpto. de Educación y Cultura, 1993.

2 José Goñi Gaztambide, Historia eclesiástica de Estella, t. 2. Las Ordenes religiosas (11311900). Gobierno de Navarra: Dpto. de Educación, Cultura y Deporte, 1990, p. 281.

Hispania Sacra, LX

121, enero-junio 2008, 143-171, ISSN: 0018-215-X 
que de esta forma y aun no profesando como monjes, pudieron recibir una educación equivalente al grado medio de estudios. Se trataba de muchachos que servían como criados de la Orden, atendiendo a las tareas encomendadas en las granjas u otras más especializadas, aunque también se dio el caso de quienes pagaban por su estancia y aprendizaje, generalmente hijos ilegítimos de familias poderosas que de esta forma cumplían con el deber de darles una buena formación para el futuro, sin sufrir la humillación de tenerlos cerca de su lugar de residencia ${ }^{3}$.

La decadencia que sufren los monasterios navarros y no solo los cistercienses en la segunda mitad del s. XV, es consecuencia de la guerra civil entre Juan I de Navarra y su hijo Dn. Carlos Príncipe de Viana, cuyas secuelas perdurarán hasta la incorporación del Reino a Castilla. Las principales familias agramontesas y beamontesas lucharán por acaparar las abadías del Císter, dándose la situación insólita de mantenerlas por dos y tres generaciones dentro de la misma familia, en un ejercicio de nepotismo bendecido por la Sede Apostólica, que no hacía por su parte otra cosa sino desarrollar la misma táctica, en uno de los periodos más oscuros de la Historia de la Iglesia que justificará la extensión de la Reforma protestante. La decadencia de los monasterios navarros avanzado el s. XV estuvo ligada a los problemas de la guerra civil que provocaron la disminuición de sus rentas, administradas por sus abades de forma particular sin hacer partícipe de ellas al cabildo, provocando con ello la confrontación con los frailes conventuales. Para tratar de sustraerse a sus efectos, los abades optaron con frecuencia por dejar de residir en las abadías buscándose otras residencias donde la vida les fuera más cómoda, dejando con ello a los monasterios sin gobierno temporal ni espiritual, en una progresiva relajación del cumplimiento de la regla monástica.

La situación cambiará en la segunda mitad del s. XVI por los nuevos vientos que soplan en la Iglesia Católica desde el concilio de Trento, pero también por el interés de la monarquía española que se apoyará en el derecho de patronato concedido en 1524 por el Papa Adriano VI al que fuera su pupilo Carlos de Gante, convertido en el Emperador Carlos V. Con no poca oposición por parte de los monasterios, empezará a exigirse el derecho de presentación real para los

\footnotetext{
${ }^{3}$ Es el caso de Carlos de Atondo, hijo natural del abogado Francisco de Atondo, descendiente de los linajes Atondo y Eguaras de Tudela, que estudió Doctrina cristiana en San Martín de Unx con el clérigo beneficiado de la parroquia. En 1563 fue llevado a casa del abad de Iranzu, educador de otros hijos de familias principales, donde aprendió los rudimentos de la lengua latina y griega, para volver a Tudela una vez reconocido por su progenitor en 1569, prosiguiendo en esta ciudad su formación en gramática y latinidad. En el testamento de su padre redactado en 1571 le dejó heredero de sus bienes, con la condición de contraer matrimonio con esposa de familia hidalga. Sin embargo su parientes paternos contestaron esta herencia, provocando un pleito de larga duración en el que perdió los derechos al mayorazgo Eguaras de Tudela (AGN, Procesos, n 100166, que dura desde 1582-1603).
} 
cargos y dignidades eclesiásticas, sin ser suficientes como hasta entonces la elección del abad por el cabildo, y la correspondiente bula pontificia de ratificación de la elección. Esta medida llevada a cabo en todas las órdenes religiosas con sede en los territorios de la monarquía hispánica, es interpretada por algunos historiadores como una fase más del proceso de castellanización de Navarra, al introducir en la jefatura monástica abades adictos a los intereses reales. En realidad supuso la reformación religiosa de los monasterios, y la vuelta a sus actividades regulares, entre ellas las referentes a la formación intelectual de los candidatos a monjes, y de los laicos que estudiaban en sus escuelas.

Sin embargo el objetivo de la Corona no era tanto el control de los establecimientos eclesiásticos navarros, sino la separación de la casa madre francesa que gobernaba los conventos navarros a través de la provincia de Aragón. En el caso benedictino se logró adscribiendo el monasterio de Irache a la congregación de $\mathrm{S}$. Benito de Valladolid. En cuanto a los monasterios cistercienses, aun cuando los planes filipinos de sujeción a la provincia de Castilla fueron favorecidos por los breves de Pio VI, Gregorio XIV y Clemente VII, la situación cambiará en el s. XVII, en el que al erigirse canónicamente la Congregación de Aragón en 1616 con el beneplácito de Paulo IV, los monasterios navarros optan por unirse a ellos. Felipe IV dio su asentimiento en 1631, obteniéndose la autorización del General de la Congregación aragonesa, y la ratificación pontifícia de Urbano VIII en bula expedida en 16344. La ruptura de toda dependencia francesa, tanto en el plano intelectual (prohibición de estudiar en universidades extranjeras), como de gobierno eclesiástico, tiene su manifestación también en la organización diocesana, consiguiéndose la separación de los pueblos del NW de Navarra de la diócesis de Bayona en 15675, para incorporarse a la de Pamplona. Todo medio era válido para sustraerse a las corrientes de la herejía calvinista que se propagaba por las proximidades de la frontera con los reinos de la Monarquía Hispánica.

Pero además la Corona impulsó la reformación de los monasterios no solo en el plano de la vida monástica, sino en el de la recuperación intelectual. Así en el s. XVII se fundó la Universidad Literaria de Irache para la formación de los monjes benedictinos dependientes de la congregación de S. Benito de Valla-

4 J. Moral, O.S.B, «La Congregación cisterciense de la Corona de Aragón y los monasterios navaros entre 1569 y 1632». Príncipe de Viana, 110-111, (1968), pp. 5-27.

${ }_{5}^{5}$ Breve de Pío V de 1566 comninando a los obispos de Bayona y Aux a nombrar vicario católico en el plazo de 6 meses. Al no hacerlo, se produce en 1567 la desmembración de los lugares de Guipúzcoa y Navarra que hasta entonces habían formado parte de dicha diócesis. Rapidamente el obispo pamplonés Diego Ramírez Sedeño tomó posesión de los arciprestazgos navarrps, siendo obligado el obispo bayonés, de religión calvinista, a aceptar la nueva situación. Vid. J. GoÑ GAZTAMBIDE, Historia de los obispos de Pamplona s. XVI, t. 4. Pamplona: Eds. Universidad de Navarra, S.A, Gobierno de Navarra, Dpto. de Educación y Cultura, Institución Príncipe de Viana, 1985, pp. 214-221.

Hispania Sacra, LX

121, enero-junio 2008, 143-171, ISSN: 0018-215-X 
dolid, y se apoyó la renovación de las escuelas de los monasterios cistercienses navarros, adelantándose a los planes regios el monasterio de Iranzu, que será el primero en recuperar el tono escolástico, gracias al impulso de sus abades formados en universidades de renombre, que entre otras cosas dinamizaron la vida escolástica y renovaron la biblioteca adquiriendo obras adecuadas para el estudio de la Teología y Humanidades. Tenemos testimonios de la existencia de una Schola de Gramática en el monasterio de Iranzu desde comienzos del s. XVI, coincidiendo con el abadiato de Rodrigo de Acedo, que llegó al cargo por resignación de su antecesor Domingo de Aoiz, obteniendo con el consentimiento de Fernando el Católico la correspondiente bula pontificia de Leon X en 1513. Este abad muy respetado por las élites navarras, representó al monasterio en las Cortes de Navarra en 1515, y como embajador de las mismas consiguió la reparación de numerosos agravios solicitados al Católico en la ciudad de Burgos, poco antes de la anexión política de Navarra a la Corona de Castilla ${ }^{6}$.

Conforme iba haciéndose anciano planeó la renuncia de la abadía en su sobrino Diego de Acedo, contando para ello con el asentimiento del Emperador y las reticencias del convento que manifestó sus reservas ya que era clérigo secular y todavía no había finalizado sus estudios universitarios en Toulouse. La formación intelectual del sobrino está documentada desde 1529 en que era clérigo estudiante, costeándose los estudios con parte de las primicias de la iglesia de Muru-Astrain que pertenecía al monasterio de Iranzuํ. La Corona aceptó en 1537 la resignación del abadiato realizada por Rodrigo de Acedo en su sobrino Diego de Acedo, gracias a las gestiones hechas en su favor por los marqueses de Cortes que acudían con frecuencia a la ciudad de Estella en la que tenían no sólo casa sino capilla funeraria en la iglesia de San Pedro ${ }^{8}$. En esta época ya tenemos datos de la existencia de una Schola de Gramática en el monasterio de Iranzu. Entre sus alumnos estuvieron Juan Díaz de Baquedano vecino de Abárzuza, que siendo de edad de 14 años solia estar en el dicho monesterio de Iranzu y escuela, y en servicio de los monjes de dicho monesterio y ayuda a dezir misa y otros servicios que le mandaban ${ }^{9}$. Al parecer era el centro de estudios

\footnotetext{
${ }^{6}$ P. Boissonade, Historia de la incorporación de Navarra a Castilla (trad. E. Ramírez Vaquero). Pamplona: Gobierno de Navarra, Dpto. de Cultura y Turismo, Institución Príncipe de Viana, 2005, p. 597: «Los tres delegados de las Cortes de Pamplona (entre ellos el abad de Iranzu), se dedicaron a estipular las garantías para la autonomía administrativa de su pais y obtuvieron que se hiciera justicia a sus agravios en la mayor parte de los asuntos» (AGN, Cortes, Legislación, leg. 1, carp. 23).

${ }^{7}$ AGN,Tribunales, Procesos, n ${ }^{\circ} 90$ de los años 1529-31/ Pleito de Diego de Acedo contra el rector de Muru-Astrain por que no le entregaba la parte que le correspondía sobre los frutos primiciales.

${ }^{8}$ AGN, Proceso 87149 del año 1566, con el conflicto planteado en la elección del abad Miguel de Azpilcueta. Dn. Juan de Benavides y Dña. Jerónima Navarra, marqueses de Cortes, eran muy apreciados por Felipe II, que les concedió la merced de residir en el palacio real de Olite, desde donde se desplazaban tanto a Estella como a su señorío de Cortes.

${ }^{9}$ AGN, Tribunales, Proceso 87149 de año 1566, fol. $125 \mathrm{v}$.
} 
preferido para la la formación de los hijos de familias importantes, algunos de ellos con defecto de nacimiento como hijos naturales o bastardos, a los que era preciso educar conforme a su rango y sin levantar murmuraciones en el lugar de residencia de sus padres ${ }^{10}$.

A la muerte de fray Diego de Acedo el convento decidió recuperar el derecho de elección de su abad, de forma que en el capítulo de comienzos de 1565 presidido por el prior de Marcilla, eligieron a fray Miguel de Azpilcueta pariente del abad difunto y de los señores de Javier. Entre sus méritos primó el de haber sido prior y maestro de novicios del monasterio. Al parecer no reunía los requisitos de ciencia y títulos universitarios que tenían sus predecesores, por lo que la Corona que ya había frustrado la elección de Martín de Rada III para la abadía de la Oliva, pide una investigación sobre Iranzu, que llevará a cabo el Fiscal del Consejo de Navarra Ldo. Cabrio de Ortega. Los frailes del convento testifican a favor del electo indicando que procedieron a su elección por ser el fraile más anciano, buen gramático, y maestro de novicios. Los testigos laicos por el contrario tenían opiniones encontradas. Así Juan de Lizarazu labrador vecino de Estella manifestó que el electo no tenía letras sino un poco de gramatica y ser monje... que hay otros monjes de tanto ser y habilidad... y que tiene dos hijos en el lugar de Ibiricu; Juan de Eguiluz encargado de la granja de Alloz que pertenecía al monasterio dijo que Azpilcueta había estudiado 8 años en la ciudad de Estella antes de entrar como novicio ${ }^{11}$. Diego de Ondériz y Baquedano, declaró que era buen gramático y buen religioso... y como tal se le dio el cargo de prior... Y que sabe de cierto que por aber querido luego que fue prior reformar algunas cosas tocantes a los religiosos, y venir a las manos con algunos de ellos amigos de la libertad... cayo en desgracia de algunos dellos, y cree que asta oy le quieren mal ${ }^{12}$.

De la investigación se desprende que el anterior abad Diego de Acedo había conseguido los correspondientes despachos de presentación de S.M. gracias a las gestiones de los marqueses de Cortes, y la bula pontificia le fue conseguida en Roma por su hermano Juan de Azedo que vivía en Tiebas. Por tanto se habían cumplido los requisitos exigidos por el Real Patronato y por la Curia pontificia. Cosa que no había sucedido con la elección de Miguel de Azpilcueta, elegido abad por el convento nueve meses después de la muerte de su precedesor, sin la preceptiva presentación real ni bula pontificia. Por ello la interven-

\footnotetext{
10 Vid. nota 2.

${ }^{11}$ Debió de estudiar en el Estudio de Gramática de Estella, que tuvo grandes maestros como el latinista y versificador Ldo. Juan Ferrer oriundo de Montoro (Teruel), que estuvo al frente del estudio estellés desde 1526-1559, por lo que probablemente fue maestro del electo abad de Iranzu. Vid. J. GoÑI GazTAmbide, «Historia del estudio de Estella», Príncipe de Viana, n 94-95, 1964, pp. 9-47.

${ }^{12}$ AGN, Tribunales, Procesos, $n^{\circ} 87149$, fols. 146, 152v, 173v.
}

Hispania Sacra, LX

121, enero-junio 2008, 143-171, ISSN: 0018-215-X 
ción del juez comisario encargado de las averiguaciones es tan drástica que se encarcela al abad Azpilcueta en Pamplona, arrastrando en su desgracia al monasterio cuyas rentas quedaron bajo secuestro. La sentencia del Consejo de Navarra de 12-12-1565 lo destituye como abad, permitiéndole volver al convento como simple monje. Y Felipe II el 29-04-1566 ordena al Consejo navarro la remisión de todo el proceso a la corte, para proceder a la provisión de la abadía de Iranzu $^{13}$. Usando del derecho de patronato el rey presentará primero a Martín de Goñi vicario de S. Cernin que preferió renunciar para evitarse conflictos, y finalmente a Domingo de Labayen.

Domingo de Labayen había sido presbítero de S. Nicolás ${ }^{14}$, ascendiendo a canónigo de la catedral de Pamplona tras doctorarse en Teología. Tuvo que hacer profesión religiosa antes de que su confirmación canónica para la abadía de Iran$\mathrm{zu}$, con la correspondiente bula pontifícia de Pio V en 1571, obteniendo tras su presentación ante el Real Patronato la ratificación regia en el cargo ${ }^{15}$. Era experto en lenguas clásicas y enseñó la lengua latina, griega y hebrea a los monjes de Iranzu ${ }^{16}$. Tuvo un papel relevante como abad mitrado en el Sínodo Diocesano convocado en Pamplona en 1576, predicando en la misa del día siguiente a la ceremonia de apertura, un sermón en latín, griego y hebreo que dejó maravillados a los asistentes ${ }^{17}$. Consiguió durante su mandato que la calma volviera al monasterio, cuyo prestigio crecerá por la Schola de gramática en la que se enseñaba latín, griego y hebreo, las lenguas más apreciadas en la formación humanística de la época. Estas herramientas lingüísticas serían de gran utilidad a los clérigos para consultar las distintas versiones de las Sagradas Escrituras, que tras depurados estudios filológicos verían la luz en la conocida como Biblia regia (por estar patrocinada por Felipe II) o Biblia Políglota de Amberes, cuyo mérito intelectual se debe a Benito Arias Montano, y su impresión a Cristóbal Plantino.

\section{LA FORMACIÓN Y EL TRABAJO INTELECTUAL DE LOS MONJES CISTERCIENSES}

La Schola de Iranzu en el último cuarto del s. XVI sobrepasa en la calidad de sus enseñanzas a la Escuela de gramática de la ciudad Estella, donde por otra

${ }^{13}$ AGN, Tribunales, Procesos, no 87149, fol. 171v. y ss, y 197.

14 J. RuIZ DE Oyaga: «Vicarios y párrocos perpétuos de la iglesia de S. Nicolás de Pamplona», Príncipe de Viana, 19, 1958, pp. 94-95.

15 AGN, Comptos, caj. 182, $\mathrm{n}^{\circ} 28$.

16 J. L. ORella UnzuÉ: «El cardenal Diego de Espinosa, consejero de Felipe II, el monasterio de Iranzu y la peste de Pamplona en 1566», Príncipe de Viana, 36, 1975, pp. 565-610. Los datos sobre Domingo de Labayen en pp. 593-595.

${ }^{17}$ Fray P. SANDoval: Catálogo de los obispos de Pamplona, Pamplona: Nicolás de Assiayn, 1614, p. 133. 
parte alcanzaron gran impulso los estudios de latinidad en los que se formaron los hijos de las familias más importantes, como Martín de Eza, Martín de Palacios, Juan Jiménez de Oco, Diego de Armendáriz. El monasterio cisterciense estellés se convirtió en pionero de la renovación intelectual de los centros del Císter navarro, siguiendole La Oliva donde Domingo de Labayen fue nombrado abad por Felipe II en 1581, y desde luego Leire del que tenemos bastantes datos a partir del s. XVII. La abadía de Iranzu que había abierto camino, continuará brillando en tiempo de Martín Xuarez monje de Veruela nombrado abad tras la partida de Domingo de Labayen al monasterio olivarense. En su época se completa la reforma del monasterio, procediéndose en 1583 a la tripartición de los bienes entre abad, convento y fábrica como era habitual en la época. Con este motivo se hace inventariación de los bienes monásticos, dándose cuenta entre otras cosas de la biblioteca de la entidad, que sobrepasa el número de 150 referencias de obras de todo tipo, aunque destacan las escolásticas, casi todas ellas de impresión extranjera que sin duda fueron adquiridas en los tiempos en que los abades de la familia Acedo y Domingo de Labayen realizaron estudios universitarios ${ }^{18}$.

Estos datos desmienten la información bastante maliciosa realizada por el duque de Medinaceli virrey de Navarra en 1569 sobre el estado en que se encontraban los monasterios cistercienses del Reino, ajustado a la regla en cuanto al estilo de la vida monástica, deplorable en cuanto a la vida intelectual. No se ha entendido hasta agora que en estos monasterios haya habido monjes letrados, ni que se haya ejercitado letras algunas en alguno dellos, más de que los sacerdotes son latinos, llanos, sin Teologia ... porque los abades pasados en lo de rescibir los religiosos no han tenido cuenta sino rescibir amigos y criados ${ }^{19}$. $\mathrm{O}$ cuando menos hay que decir que el diagnóstico no correspondía a la realidad en los monasterios de Iranzu ni de Leire, por cuanto la propia Orden se preocupaba enormemente por esas fechas de la formación de sus frailes, tal y como se recoge en los capítulos de visita redactados por el Vicario general del Císter tras la visitación de los monasterios navarros. Aunque sobre dichas visitas no se ha conservado más documentación que la del monasterio de Leire, cabe deducir que el contenido de las reformas ordenadas por los visitadores de la Orden sería similar para todos los monasterios cistercienses navarros ${ }^{20}$.

${ }^{18}$ AGN, Comptos, caj. 182, $\mathrm{n}^{\circ} 72$.

${ }_{19}$ AGS, PR, 23, n 34.

${ }^{20}$ Del archivo de Iranzu quedan pocos testimonios, pues a fines de marzo de 1813 se incendió el convento de San Francisco de Estella, donde años antes habían ido a parar los fondos archivísticos del monasterio que se quemaron en su mayoría. Solo se salvaron los que posteriormente la Desamortización eclesiástica llevó al depósito de la Delegación de Hacienda Estatal en Navarra. De ellos tres legajos se encuentran actualmente en la Sección Clero del Archivo General de Navarra, y un códice conocido como Libro Rubro está en la Sección Clero del Archivo Histórico Nacional de Madrid. Llamado así

Hispania Sacra, LX

121, enero-junio 2008, 143-171, ISSN: 0018-215-X 
Los datos de la visita del abad de Poblet Juan de Guimerán a Leire en 1582, demuestran que encontró a la comunidad legerense en bastante mejor estado que el que se deduce de los informes que tenía Felipe II. Sus mandatos sobre la forma de llevar la vida monástica son interesantes porque explican la existencia de determinados libros en la biblioteca y el coro:

- El libro de los ussos y diffiniciones sea ahincado en el coro delante la silla de prior con cadenilla de fierro.

- El libro que se llama Cateçismus del Sacro Concilio Tridentino sea interpretado por el prior, y si estuviere grabado (enfermo) sea elegido otro monje sabio que declare el dicho libro Catecismo.

- El exercicio de los novicios sea despues del oficio divino, decorar el Psalterio de David y los Cánticos feriados. Hechos profesos primero estudiaran el canto, segundo hasta que sean buenos gramaticos de latinidad.

Assi como la liçion de los graves autores sea grande regalo para los monjes letrados, mandamos...al Sr. abbad y a los religiosos que los libros del doctor Cenoz ${ }^{21}$ abad no saquen de la librería en la cual estan, sino que esten alli comunes $^{22}$.

Siempre acordes con la Regla de San Bernardo y las disposiciones del Concilio Tridentino, informan sobre los requisitos intelectuales requeridos para la aceptación de novicios en los monasterios cistercienses, que eran el conocimiento de literatura (entendida como capacidad de leer y escribir), de la que se realizaba un examen previo a la recepción de los novicios. Esto explicaría que durante el noviciado, una de las principales actividades de los candidatos a monjes fuera la de escribir los libros litúrgicos necesarios a la comunidad. En el s. XVI se hace especial incidencia en el Psalterio, pero tal actividad se podría extender para el resto de libros necesarios al culto divino. Por tanto la producción de los scriptoria cistercienses navarros de los que nos han quedado pocas muestras debido a la Desamortización eclesiática decimonónica cuyas consecuencias fueron desastrosas para el patrimonio librario navarro, era mucho más rica de lo que pudiera sospecharse a través de los testimonios conservados. Algunos ejemplos como el Sacramentario cisterciense de Fitero, cuya escritura y decoración lo hacen uno de los ejemplos más interesantes del gótico cistercien-

porque los epígrafes están rubricados, contiene una relación de propiedades y pechas pagadas por los collazos del monasterio en los s. XIII-XIV. (Vid. J. M J JimENo JURío, «El libro rubro de Iranzu», Príncipe de Viana, 121 (1970), pp. 221-26.

${ }^{21}$ El abad de Leire doctor en Teología, había destacado al pronunciar el sermón en la Misa del Espíritu Santo con que se inaguró el Sínodo Diocesano de 1576. Vid. fray P. SANDoval, Catálogo de los obispos de Pamplona. Pamplona: Nicolás de Assiayn, 1614, p. 133.

${ }^{22}$ AGN, Clero, Leire, caj. 33954, nº 169. 
se del s. XIII ${ }^{23}$. O los fragmentos de Antifonarios de Iranzu, también del s. XIII, conservados en la encuadernación de libretos del s. XVIII ${ }^{24}$, son muestras de lo actividad de los florecientes scriptoria del Císter navarro en la E. Media. Dicha actividad tuvo continuidad en la E. Moderna, aunque en un estilo más acorde con los gustos estéticos de la época, utilizándose la llamada letra de cantorales de la que hay tantos ejemplos en los tratados de caligrafía española.

La fase siguiente de formación de los monjes tras su profesión duraba unos cuatro años, en los que se seguía un plan de estudios a cargo de un maestro, que impartía enseñanzas de Canto litúrgico, Latinidad y Sagradas Escrituras. La necesidad de contar con buenos maestros en Artes y Teología para formar a los candidatos a recibir la ordenación sacerdotal, hizo que los abades cistercienses navarros consideraran conveniente enviar a los monjes más dotados a estudiar a las universidades. Como miembros del brazo de la clerecía en las Cortes de Navarra, consiguieron el apoyo de esta institución para solicitar en las Cortes de Tudela de 1583 y conseguir de Felipe II un cupo de 12 plazas para estudiar Artes y Teología en la universidad de Alcalá de Henares, alojándose en el colegio de S. Bernardo de la universidad alcalaína ${ }^{25}$. En1586 el abad de Poblet visitador general nombrado por el General de la Orden del Císter, pudo comprobar a su paso por los monasterios de La Oliva, Fitero, Leire e Iranzu que tal medida estaba poniéndose en práctica ${ }^{26}$. Con el paso del tiempo, parece que fue el monasterio de Fitero el más interesado en enviar a sus monjes a estudiar a las universidades de Salamanca, Alcalá y Lérida.

Aunque en los monasterios cistercienses navarros es difícil rastrear uno de los indicadores de su nivel intelectual pues apenas hay datos de sus bibliotecas, podemos suponer gracias al inventario realizado en la tripartición de bienes del monasterio de Iranzu en 1583, que el estado del Císter navarro no era tan calamitoso como que se deduce de las informaciones enviadas a la corte por las autoridades reales en Navarra, y que por el contrario la preparación de sus abades y maestrecuelas gozaba de buena salud intelectual. El análisis de dicho inventario sorprende por la cantidad de obras correspondientes a la primera mitad de la centuria, casi todas ellas editadas fuera de los territorios de la monarquía hispánica. Lo que se explica por la tradicional querencia de los navarros a realizar estudios superiores en universidades extranjeras (París para estudios de Filosofía y Teología, Toulouse y Bolonia para estudios jurídicos). Tendencia que cambiará bruscamente con la prohibición de Felipe II de estudiar en universidades de países sospechosos de herejía, lo que afectó principalmente a las situadas en Francia.

\footnotetext{
${ }^{23}$ Conservado en la actualidad en el Archivo General de Navarra.

${ }^{24}$ AGN, Clero, Iranzu, caj. 33906, $\mathrm{n}^{\circ} 48$.

${ }_{25}$ Dicha merced fue comunicada al Reformador general de la Orden del Císter en 1584-01-05 Madrid (AGS, Cámara de Castilla, Libro 253, ff. 112-112v).

${ }^{26}$ AGN, Comptos, caj. 182, nº 76.

Hispania Sacra, LX

121, enero-junio 2008, 143-171, ISSN: 0018-215-X
} 
Todo lo contrario de lo sucedido en la primera mitad de s. XVI, en la que París era el destino preferido por la clerecía navarra que iba a realizar estudios universitarios, sobrepasando la diócesis pamplonesa a cualquier otra diócesis española en el número de estudiantes que frecuentaban las aulas parisinas ${ }^{27}$. Quienes no contaban con tantos recursos se conformaban con Toulouse como sucedió con Diego de Acedo que sería abad de Iranzu. Ello explicaría la abundancia de libros editados en Francia que formaban parte de la biblioteca de este monasterio en el XVI, procedentes de París y Lyon en su mayoría. Aunque también los había editados en Basilea y Venecia, de editores interesados en dar a conocer obras griegas. Por el contrario apenas encontramos libros impresos en Amberes, Lovaina, Roma, ni en los grandes centros editoriales castellanos como Alcalá de Henares o Salamanca. Por tanto el núcleo más importante de la librería de Iranzu se formó a través de las adquisiciones de los abades de la familia Acedo, incorporándose en la segunda mitad de la decimosexta centuria las obras imprencindibles requeridas por el Concilio tridentino, y las ediciones y trabajos preparatorios sobre Sagradas Escrituras realizadas por Arias Montano.

La comunidad de Iranzu apenas estuvo interesada por la controversia entre Protestantismo y Catolicismo, y sí en cambio por surtirse de lo necesario para una buena schola de gramática, promocionando el de la filología tanto latina como griega y hebrea. En su biblioteca estuvo todo lo imprencindible para los Studia Humanitatis, dando enorme importancia al conocimiento de las lenguas clásicas para lo que contó con gramáticas, diccionarios, más los textos más significativos de autores latinos (Virgilio, Horacio, Teócrito, Séneca, Lorenzo Valla, Pico de la Mirándola; retórica de Cicerón y Quintiliano; dialéctica de Jerónimo Pardo), y de autores griegos con obras escritas en esa lengua (Homero, Platón, Aristóteles, las comedias de Aristófanes, Luciano de Samosata); obras en hebreo (el Antiguo Testamento, la Historia de Flavio Josefo). Estaban representados los príncipes del humanismo europeo, especialmente Budeo y sus comentarios de la lengua griega, y parte de la obra didáctica de Luis Vives. Complementados con otras de Historia (Tito Livio, Suetonio, Valerio Máximo, autores que escribieron sobre Historia antigua como Eusebio de Cesarea, el falso Beroso de Caldea). Obras de Geografía de Ptolomeo, la descripción de Grecia, el libro de las maravillas del mundo de Solino.

No faltan como es lógico los libros necesarios a la vida eclesial, tanto en lo referente a la regla monástica (vida de $\mathrm{S}$. Bernardo de Claraval), comentarios a las partes más significativas de la misa (comentarios a las epístolas, evangelios, sermones), celebración de los oficios divinos, de los sacramentos, apologías de

27 R. García Villoslada, La universidad de París durante los estudios de Francisco de Vitoria O.P. (1507-1522). Roma, 1938, pp. 373-379. El autor recoge un total de 31 estudiantes navarros en París entre los años 1521-1535, aunque ninguno de ellos llegó a ser abad de Iranzu. 
la vida de Cristo, los profetas, los salmos. Además los fundamentos de la doctrina teológica (en especial Sto. Tomás de Aquino, y los comentarios de Cayetano de Vio, Conrado Klingo, las sentencias de los grandes autores medievales como Pedro Lombardo, Duns Scoto, S. Alberto Magno). Las lecturas espirituales y vidas de Santos con especial interés por los de la iglesia oriental (Orígenes, S. Epifanio obispo de Constantinopla, S. Cirilo patriarca de Alejandría, San Basilio Magno, S. Eusebio obispo de Cesarea, S. Cipriano obispo de Cartago) pero también el monacato de la iglesia occidental (Simón de Casia, S. Hilario de Poitiers, S. Isidoro de Sevilla). Los dos Derechos, el civil (Justiniano, Guillermo cazador obispo de Alguer, Rofredo Beneventano, pero también autores contemporáneos como Tiraquello, Domingo de Soto, Guillermo Budeo) y canónico (Summa Silvestrina, Decretales, Clementinas). Todo dentro del más puro espíritu de renovación eclesiástica, controlada por la ortodoxia representada por autores como Pedro Canisio, Alberto Pighio.

E incluso los libros necesarios para la salud temporal de los monjes, obras de medicina (Dioscórides, Guido de Chauliac, Avicena, Paulo de Egina, Bertruccio de Bolonia) y botánica (Dioscórides) consultadas por los frailes que se ocupaban de la curación de sus hermanos, ya que la Regla de S. Bernardo como bien se encargan de recordar los visitadores de la Orden, prohibía la entrada en el convento de médicos seglares: «Mandamos en virtud de Santa obediencia a los frayles cirujanos, que no puedan salir del monasterio a curar ni afeytar, sino que sea alguna persona muy de la obligacion del convento. Ni puedan tampoco en el monasterio admitir a secular ninguno para lo dicho, menos que con licencia expressa del señor abad ${ }^{28}$. También libros de zoología necesarios sin duda para la curación de los rebaños de sus granjas (Aristóteles y su Historia de los animales), y la Historia natural de Plinio. En definitiva todo lo necesario para la autosuficiencia de monasterio sin dar la espalda a las tendencias espirituales, culturales y científicas de la época, que situan a la comunidad cisterciense de Irache en contacto con las corrientes del mundo exterior, en una relación más cosmopolita en la primera mitad del XVI, más cerrada en el periodo siguiente conforme los mandatos de la Contrareforma católica fueron acabando con la apertura mental y el optimismo del periodo humanista.

El inventario que se analiza a continuación, redactado en una correcta escritura humanística cursiva, presenta sin embargo las dificultades habituales a la hora de interpretar su contenido. Escasa precisión en la identificación de los datos (tanto autores, como títulos y lugares de edición) que dificultan la localización de las referencias. No obstante, conocida la trayectoria formativa de los abades de Iranzu, y en especial de Miguel de Aoiz, hay que pensar que una par-

${ }^{28}$ Visitación de fray Joseph Serra abad de Poblet, vicario general de la Congregación, que gira visita a Leire en 1675. AGN, Clero, Leire, $\mathrm{n}^{\circ} 170$.

Hispania Sacra, LX

121, enero-junio 2008, 143-171, ISSN: 0018-215-X 
te importante de los libros proceden de Francia. Lo ratifica la querencia tradicional de la clerecía navarra hacia las universidades de este pais, y la oposición hacia todo lo que viniera de Castilla. Y ello debido a que la mayor parte del clero era de filiación agramontesa, y su sentimiento de lealtad hacia los destronados reyes de la casa de Albret permanecía muy vivo todavía en la primera mitad del s. XVI.

Por otra parte, el renacimiento cultural cisterciense no es exclusivo del reino de Navarra, sino que se produce en otros establecimientos hispanos que siguen las mismas pautas, considerando el conocimiento de las lenguas antiguas (hebreo, latín, griego) como algo necesario para el estudio de las Sagradas Escrituras. Hay pues un cierto paralelismo entre los fondos bibliográficos de los monasterios cistercienses de la época. Son estos factores histórico culturales los que nos mueven a precisar la identificación de los registros señalados, aportando los datos completos incluso de la edición cuando se ha encontrado una referencia claramente identificable, y avisando con un tal vez en los casos en que pudiera haber ciertas dudas. Cuando se encuentran varias ediciones de una obra en distintas ciudades europeas, no nos pronunciamos por ninguna de ellas. Se ha considerado más importante identificar los títulos, pues a través de ellos podemos hacenos una idea de las materias que tenía la biblioteca. Se han expresado los nombres de los autores tal y como vienen en la portada del libro, para dar pistas a posibles consultantes de este trabajo, ya que la normalización onomástica no es de gran ayuda a la hora de calibrar las distintas variantes con las que el investigador debe jugar, dado el escaso cuidado puesto por el escribano al realizar el inventario.

\section{APÉNDICE DOCUMENTAL}

1583-01-07.- Iranzu / Inventario de la Librería del monasterio de Iranzu29. AGN, Comptos, caj, 182, no 72, fols. 24r-27r.

\footnotetext{
${ }^{29}$ La identificación de las referencias se ha realizado consultando el Catálogo Colectivo de Patrimonio Bibliográfico centralizado en la BN de Madrid. La descripción de los registros se hace siguiendo las ISBD (A): Descripción bibliográfica internacional normalizada para publicaciones monográficas antiguas, Madrid: Anabad, Arco libros S.L., 1993, manteniendo la disposición de datos que aparece en la portada de los libros, en cuyos títulos lo frecuente es que el autor vaya tras el título. Además pueden cotejarse diversas tipobibliografías, como la de J. MARTín ABAD: La imprenta en Alcalá de Henares (1502-1600). Madrid: Arco Libros, 1991; C. PÉRez PASTOR: La imprenta en Medina del Campo. Valladolid: Consejería de Cultura y Turismo, 1992 ( $2^{\text {a }}$ edic. facsimilar); L. RuIz FIDALGO: La imprenta en Salamanca (1501-1600). Madrid: Arco Libros, 1994; A. SAN VicENTE PINO: Apuntes sobre libreros, impresores y libros localizados en Zaragoza entre 1545-1599. Vol. I, Los libreros, Vol. II, Los impresores. Zaragoza: Gobierno de Aragón, Dpto. de Cultura y Turismo, 2003; A. PÉREz GoYENA. (SJ): Ensayo de bibliografía navarra. Desde la creación de la imprenta en Pamplona hasta el año 1910.
} 
En el dicho monesterio de Irançu, a siete días del mes de Henero del año mill quinientos ochenta y tres, el dicho Sr. Licenciado Miguel de Aoiz comissario susodicho, hizo inventario y memorial de la librería que se allo en el dicho monesterio, que son los cuerpos siguientes:

-Primeramente las obras de San Gregorio en un cuerpo que es de la impression de Guillermo Desmor(sic) en Paris/ Divi Gregorii Papae huius nominis primi, cognomento Magni, Omnia quae extant opera nunc iterum acuratione diligenti a mendis multis repurgata...cum indice duplici...accessit insigne corollarium e Cartusia Parisiensi (tomus primus-secundus). Parisiis: apud Carolam Guilland et Guilielmum Desboys, 1551.

2-Item las obras de Sancto Ambrosio en un cuerpo y encuadernados en bezerro, y de la misma impresión/ Opera Divi Ambrosii Mediolanensis episcopi, quatenus in hunc usque diem ubi extare noscuntur (tomus primus-quintus). Parisiis: apud Carolam Guillard et Guilielmum Desboys, 1549 (1550).

3-Item las obras de Sant Joan Grisostomo en quatro cuerpos enquadernados en bezerro, que son impresos en Paris en la impresion de Guilelmo Laolanto Primus...quartus tomus operum divi Ioannis Chrysostomo, archiepiscopi Constantinopolitani, ea complectens.. Parisiis: apud Guillielmum Roland, 1546.

4-Item las obras de Sanct Hieronimo en 7 cuerpos enquadernados en bezero, impresos en Basilea por Joan Probenio(sic)/ Omnium operum Divi Hieronymi Stridonensis. Apud inclytam Basileam: ex acuratissima officina Frobeniana, 1516.

5-Item las obras de Sant Ephifaneo en un cuerpo, enquadernadas en bezerro, impresas en Paris por Calola Guiar(sic)/ Divi Epiphanii episcopi Constantiae...Contra octoginta haereses opus...Parisiis: apud Carola Guilliar, 1549.

6-Item las obras de Sant Bernardo en un cuerpo, encuadernadas en bezerro de la impresión de Calola Guiar(sic) en Paris/ Divi Bernardi...abbatis Clarevallensis...Opera in lucem denuo foelici...exeunt. Parisiis: apud Carolam Guillard, vidua Claudii Chevalloni, et Guilelmum Desbois, 1551.

7- Item las obras de Sant Cirilo en un cuerpo, encuadernadas en bezerro, impresas en Basilea por Andrea de Catardem(sic)/ Divi Cyrilli Patriarchae Alexandrini episcopi, in evangelium Ioannis comentaria...Georgio Trapezuntio interprete...Basileae: apud Andream Cratandum, 1524.

8-Item las obras de Sant Basilio Magno en un cuerpo, impresas en Basilea por Probeniano(sic)/ Tal vez Omnia D. Basilii Magni...quae extant opera: iuxta argumentorum congruentiam in tomos partita quatuor...Iano Cornario medico

\footnotetext{
Vol. 1. Pamplona: Diputación Foral, Institución Príncipe de Viana, CSIC, 1947; M. I. Ostolaza ElizONDO: Impresores y libreros en Navarra durante los s. XV-XVI. Pamplona: Universidad Pública de Navarra, 2004.

Hispania Sacra, LX

121, enero-junio 2008, 143-171, ISSN: 0018-215-X
} 
physico interprete. Basileae: ex officina Frobeniana, apud Hieronymum Frobenium et Nicolaum Episcopum, 1540.

8 bis-Item las obras de Simon de Casea en un cuerpo, encuadernadas en papelon y cuero negro, de la impresión de Vcario Corbino(sic)/ Simonis de Cassia...De gestis Domini Salvatoris, in quatuor evangelistas libri quindecim. Apud Sanctam Ubiorum Coloniam: ex officina Eucharia Cerviconi, 1540.

9-Item las obras de Sant Cipriano en un cuerpo, de badana colorado/ Divi Caecilii Cypriani episcopi Carthaginensis opera. Diversas edics. en ciudades europeas.

10-Las obras de Sant Ylario en un cuerpo/ Divi Hilarii Pictavorum episcopi lucubrationes quotquot extant olim per Desiderium Erasmum Roterodanum...emendatam. Diversas edics. en ciudades europeas.

11-Las obras de Sant Ysidro(sic) en dos cuerpos/ Tal vez Praeclarissimum opus divi Isidori Hispalensis quod Ethimologiarum inscribitur. Impresum Parrhisii, sumptibus Ioannis Petit, 1520.

12-La Biblia Sacra en un cuerpo/ Impreciso.

13-Tres tomos de concilios/ Impreciso.

14-Un libro de restitucion de Cordova, de la impresión de Alcala/ Libellus de detractione et famae restitutione, fratris Antonii Cordubensis, de Sacro ordine Minorum, annotationes eiusdem in tractatum De secreto magistri Soto. Compluti: ex officina Ioannis Brocarii, 1555.

15-El libro de Bartolome Fumeo, que es Suma de Inquisidores/ Suma sive aurea armilla Bartholomei Fumi Placentini, Ordinis Praedicatorum hac haereticae pravitatis inquisitoris...breviter omnia continens quae in iure canonico apud theologos...Varias edics. en diversas ciudades europeas.

16-La Apologia de Mauro, impresa en Paris/ Apologia in duas partes divisa pro iis, qui ex patriarcharum Abrahae videlicet, Isaac et Iacob reliquis sati, de Christo Iesu et fide catholica pie ac sancte sentiunt, in archiepiscopum Toletanum et suos asseclas, authore Fr. Henrico Mauroy familiae S. Francisci. Parisiis: apud Vivantium Gaultherot sub intersignio D. Martini et Sebastianum Nivellum, 1553 (excudebat Lutetiae Parisiorum Michael Fazendat, 1552).

17-Las obras del padre Andrea de Vega/ Tal vez Tridentini Decreti, De iustificatione et defensio libris XV distincte..autore fratre Andrea a Vega, ordinis Minorum. Varias edics, en Venecia, Alcalá de Henares.

18-Las obras de Medina, de Penitencia/ Breve instruction de como se ha de administrar el sacramento de la penitencia, dividido en dos libros, compuesto por fray Bartholome de Medina, de la Orden de Santo Domingo. Varias edics. en Huesca, Salamanca, Zaragoza. 
19-Las obras de las Catolicas Instituciones de Simancas en Alcala impresas/ Institutiones Catholicae Iacobi Simancae Pacensis episcopi: institutionibus liber ad praecavendas et extirpandas haereses ad modum necessarius. Compluti: apud Andream de Angulo, 1569 (1570).

20-Las obras de Soto en tres cuerpos/ Tal vez Fratris Dominici Soto...ordinis praedicatorum, De iustitia et iure libri decem...Salmanticae: excudebat Ioannes Baptista a Terranova, expensis Benedicti Boyerii, 1569 (1568).

21-La Jerarcia(sic) ecclesiastica de Alberto Piçio(sic) composis/ Hierarchia Ecclesiastica assertio libris sex comprenhensa, authore Alberto Pighio. Coloniae Agrippinae: apud haeredes Arnoldi Birckmanni, 1572.

22-Las obras de Escoto en dos cuerpos enquadernados en tablas/ Tal vez Questiones quolibetales ex quattuor Sententiarum voluminibus, a doctore suvbtilissimo edita, Ioanne Duns Scoto, Ordinis minorum. Varias edics, en diversas ciudades europeas.

23-Tiraquelo, De nobilitate et primogenitura/ Andreae Tiraquelli, De nobilitate et de iure primigeniorum. Varias edics. en diversas ciudades europeas.

24-El concilio Tridentino/ Tal vez Canones et decreta sacrosanti Oecumenici Concilii Tridentini, sub Paulo III, Julio III et Pio IV Pontific.Maximo celebrat. Canones et decreta. Salmanticae: Excudebat Joannes Babtista a Terranova, 1568 (1569).

25-Lodovico Çeli Rodigino, de las leciones antigas/ Sicuti antiquarum lectionum commentarius concinnarat olim vindex Ceselius, ita nunc eosdem per incuriam interceptas, reparant Lodovicus Caelius Rhodiginus. Venetiis: in aedibus Aldi et Andrae Soceri, $1516^{30}$.

26-Filion Judeo, en latin y griego, en vezerro/ Philonis Iudaei...Lucubrationes omnes quotquot haberi potuerunt, nunc primum latinae ex graecis factae per Sigismumdum Galenium. Basileae: apud Nicolaum Episcopum Iuniorem, 1554.

27-Petro Canisio en dos cuerpos, enquadernados en bezerro/ Tal vez Commentariorum De verbi Dei corruptelas...tomi duo...Ingolstad: 1583 (y edics. en otras ciudades europeas).

28-Cathecismo Catholico de Miguel episcopo Maspurgense/ Catechismus Catholicus...quondam Dn. Michaelis episcopi Mespurgensis...Coloniae: apud haeredes Iohannis Quentel et Gervinum Calenium, 1562.

\footnotetext{
${ }^{30}$ Se trata de Lodovico Ricchieri, profesor de Gramática en Milán y Padua a comienzos del s. XVI, autor de las Antiquarum lectionum que tanto se difundieron por Europa. Vid. J. L. RuIZ MigueL, «Las lectiones Antiquae de Celio Rodigino y su importancia en la transmisión de la cultura grecolatin», IV Congreso Internacional de Humanismo y pervivencia del mundo clásico. Alcañiz, 9-14 Mayo 2005.
} 
29-El tercero tomo de Joanes Arborea impresso en Paris/ Tertius tomus Theosophiae Ioannis Arborei Laudunensis...complectitur sanam et luculentam, in omnis Divi Pauli Epistolas explanationem, in qua sacrorum et scholasticorum doctorum sententiae discutiuntur. Parisiis: apud Ioannem de Roigni...sub insigni quatuor elementorum, 1553 (excudebat Matthaeus David).

30-Las obras de Joan Jarson/ Tal vez Ioannis Gersonis, De imitatione Christi, De contemptu mundi. Compluti: in aedibus Ioanni Brocensi, 1554 (y otras edics. en diversas ciudades españolas).

31-Las obras de Francisco Balduino impresas en Paris/ Tal vez Tractatus de pignoribus et hypotecis, autore D. Antonio Negusantio, Francisco Balduino et Hugone Donello, quibus D. Petri Vanderani tractatus De privilegiis creditorum. Lugduni: apud haeredes Iacobi Iuntae, 1562.(no hemos encontrado la edición de París).

32-Rupertus in Bibliam/ Tal vez Ruperti abbatis monasterii Tuitiensis...operum, tomus primus-secundus. Coloniae Agrippinae: apud haeredes Arnoldi Birckmanni, 1577.

33-Otro tomo de Joanes Arborea sobre los evangelistas/ Doctissimi et uberrimi commentarii Ioannis Arborei... in quatuor Domini Evangelistas; in quibus sacrorum doctorum sententiae discutiuntur et perniciosae quarundam interpretum assertiones recuincuntur; adiectus est huic operi laboriosissimo iudex. Parisiis: apud Ioannem de Roigny, 1551.

34-Los sermones de Lorenzo Justiniano/ Tal vez Divi Laurentii Iustiniani protopatriarchae Veneti opera... Edics. en diversas ciudades europeas.

35-Fray Diego de Estella sobre San Lucas/ Fratris Didaci Stellae...in sacrosanctum Iesu Christi Evangelium secundum Lucam, enarrationem tomus primus-secundus. Varias edics. en Salamanca, Alcalá, Amberes, etc.

36-Ector Pinto sobre Essayas/ Fratris Hectoris Pinti Lusitani...in Esaiam Prophetam commentaria. Varias edics. en Amberes, Lyon, 1567.

37-Las obras contra los judios de Petro Galatino/ Petri Galatini opus toti christianae reipublicae maxime utile, De arcanis catholicae veritatis contra obstinatissimam Iudaeorum nostrae tempestatis perfidiam, ex Talmud aliisque hebraicis libris nuper excerptum et quadruplici linguarum genere eleganter compertum. Varias edics. en diversas ciudades europeas.

38-Unas obras de San Luquerio obispo de Leon(sic), sobre la Biblia/ Tal vez Divi Eucherii episcopi Lugdunensis, Commentarii in Genesim et in libros regum. Romae. Apud Paulum Manutium, Aldi filii, 1564.

39-San Pagnino sobre la Escritura Sagrada/ Tal vez Solida et absoluta Isagoge seu introductio in Sacras litteras et mysticos Sacrae Scripturae intellectus 
libri XX, authore Sancte Pagnino Lucensi. Coloniae: apud haeredes Ioannis Quentel et Gervinum Calenium, $1563^{31}$.

40-Los Commentarios de Cayetano sobre las obras de Moysen/In Pentateuchum Mosis iuxta sensum quem dicunt liberalem commentarii. Romae: apud Antonium Bladum, 1531 (1532).

41-San Agustin sobre los Salmos/ Divi Aurelii Augustini Hipponensis episcopi, Enarrationes sive comentarii in Psalmos mysticos. Parisiis: apud Ioannem Roigny....excudebat Antonius Turrianus, 1549.

42-Los Sermones de Guillermo de Peraldo/ Question adiuncta ad communem utilitaten predicantium habes in hoc volumine...magistri Guilhermi de Peraldo, episcopi Lugdunensis... In egregia civitate Avinionem: per honestum virum magistrum Iohannem de Cauney impressorem, 1519.

43-Questiones morales de Petro Tarateti (sic)/ Questiones morales magistri Petri Tatareti...in octo capita distincte....doctissime ab eodem disputate atque discusse nec sequitur adnotata. Venundantur Parrhisiis: per Gaufridum de Marnef, $1504{ }^{32}$.

44-Los sermones de Joanes Aulino (sic)/ Tal vez Itinerarium Paradisi...magistri Iohannis Raulin, Ordinis Cluniacensis, complectens sermones de Penitentia et eius partibus; cui adiuncti sunt ... sermones eiusdem...de matrimonio et viduitate. Varias edics, en París, Lyon entre 1518-152433.

45-San Agustin, de Civitates Dei, en pergamino/ Probablemente manuscrito de la obra de San Agustin, De civitate Dei libri XXII.

46-Sermones del maestro Ambrosio/ Tal vez Tertia pars operum Sancti Ambrosii episcopi Mediolanensis..in hac parte habetur hec, epistolarum opus...opus sermonum, Varias edics. en Basilea, a partir de 1516.

${ }^{31}$ El dominico Santos Pagnini de Lucca, es autor de esta obra y el Liber interpretationis impreso en 1528. Tradujo asímismo la Biblia (Antiguo y Nuevo Testamento) en 1527. Vid. L. SAGALÉS SISQUELLA, «La hermenéutica simbólica de fray Andrés de Acítores», Humanismo y Císter, I Congreso Nacional sobre Humanistas españoles, León, Universidad, Serv. Publicaciones, 1996, pp. 65-85, y en concreto p. 78.

32 Pedro Tatarero, seguidor de las doctrinas de Scoto, estudió en el Colegio de Monteagudo de la universidad parisina, licenciándose en Teología en 1496, obteniendo el Doctorado en 1500 (R. GARCía Villoslada, La universidad de París... pp. 165-168.

33 Juan Raulin. Gran maestro del Colegio de Navarra fallecido en 1496, consejero de obispos y próceres de Francia, fue una de las figuras más relevantes de la universidad parisina, a cuyos honores renunció entrando en el convento de Cluny. Nominalista de la escuela de Gerson y Lemaistre, se lamentaba de la preponderancia de la Teología especulativa sobre la práctica o moralista. (Vid. R. GARcía VILloslada, La universidad de París... p. 61. No hay que confundirlo con Juan Reuchlin, que no escribió sermones sino obras sobre cabalística cristiana.

Hispania Sacra, LX

121, enero-junio 2008, 143-171, ISSN: 0018-215-X 
47-Cayetano sobre los Reyes/ Tal vez Reverendissimi Domini Domini Thomae a Vio Caietani, Cardinalis Sancti Xysti, In omnes authenticos Veteris Testamenti historiales libros commentarii. Edic. en diversas ciudades europeas.

48-Joanequio contra el Lutero/ Enchiridion locorum communium adversus Lutherum et alios hostes Ecclesiae, Ioanne Eckio authore. Lugduni: Mathias Bonhome 1538, o edics. posteriores.

49-Guillermo Bernardo Francisco, De sepultura. No ha sido identificado.

50-Aurea rosa del maestro Silbestro/ Aurea rosa id est preclarissima expositio super evangelia totius anni, de tempore et de sanctis...Silvestro de Prierio, sacri ordinis fratrum Predicatorum observanti. Varias edics., en Bolonia, Lyon, etc.

51-Los sermones dominicales de Gabriel Esperenssi/ Sermones dominicales hyemales...viri magistri Gabrielis Spireu. Hagenau: impensis Ioannis Rymman de Oringan: in officina Henrici Grau, 1517.

52-Los lugares comunes de Theologia de Conrrado Clingi franciscano/ Loci communes Theologici...D. Conradi Klingii. Coloniae: apud haeredes Arnoldi Birckmanni, 1562, o edics. post. en París.

53-Agustino Euchio sobre el Reconocimiento de la verdad ebraica/ Recognitio Veteris Testamenti ad hebraicam veritatem, collata etiam editione Septuaginti interpreti. Venetiis: in aedibus Aldi et Andreas Soceri, 1529.

54-El Salterio en ebreo y latin/ Tal vez Davidis regis ac prophetae aliorumque sacrarum vatum Psalmi, ex hebraice veritate in latinum carmen a Benedicto Aria Montano...conversi, cum argumentis et elucidationibus ...eiusdem interpretis...adiunctis. Antuerpiae: ex officina Christophori Plantini, 1574.

55-La genealogia de los barones y mugeres de la Escritura Sagrada/ Index et genealogiae virorum ac mulierum qui in Sacra Scriptura continentur: simul cum homonymia eorundem ad eius historicam intelligentiam maxime conducamus, autore F. Hieronymo Laureto. Venundantur Barcinonae: in aedibus Michaelis Ortis, 1568 (Petrus Reignerius).

56-Cipriano monaco, en la profecia de Nau/ Commentaria in prophetam Nahum, Cypriani monachi cysterciensis, divinae legis interpretis. Lugduni: apud Guillielmum Rovilium, $1563^{34}$.

57-Jeorgio Paquinerio, sobre las diez cartas de S. Dionisio/ Georgii Pachymerae paraphrasis in omnia Dionysii Areopagitae, Athenarum episcopi, opera quae extant. Parisiis: Guil. Morelius, 1561.

\footnotetext{
${ }^{34}$ Cipriano de Huerga fue maestro de fray Luis de León y Benito Arias Montano. Manejó fuentes hebreas y griegas para sus trabajos. Vid. J. L. MONGE, J. L. GARCíA, «Comentario al profeta Nahúm de Cipriano de la Huergaen Humanismo y Císter, I Congreso Nacional sobre Humanistas españoles. León, Universidad, Sec. Publicaciones 1996, pp. 47-52.
} 
58-De Regimine sanitatis, de Betruçio Bononiense/ Collectorium ...totius fere medicine Bertrucii...in quo infrascripte continentur, De regimine sanitatis...de egritudinis particularibus que sunt a capite usque ad pedis...de crisi...de venenis...Lugduni. Per Claudium d'Avost als Troys, impensis Bartholomei Trote, 1509.

59-Theocrito siracusano en un libro pequeño/ Tal vez Theocriti Syracusani Ydillia triginta sex, Helio Eobano interprete. Haganoe: Per Ioan. Secerium, 1530 (1531).

60-Aristoteles sobre la Ystoria de los animales/ Tal vez Aristotelis Stagiritae libri omnes ad animalium cognitionem attinentes, cum Averrois Cordubensis variis in eorumdem commentariis. Venetiis: apud Iuntas, 1550 (apud haeredes Lucaeantonii Iunctae florentini).

61-Commentaria de Joanes Tagaurcio/ Joannes Tagautii autor de obras de cirugía.

62-Diascoridis opera/ Pedacii Dioscoridae Anazarbei: De materia medicinali libri sex (diversos intérpretes).

63-La cirugia de Guidon Cauliaco/ No hemos podido precisar la obra de Guido de Chauliac ni encontrar edic. anterior a la fecha del inventario, pero pudo ser parecida a Chirurgia magna Guidonis de Gauliaco, nunc demum suae primae integritati restituta a Laurentio Louberto. Lugduni: in officina Q. Philipi Tinghi (apud Simphoranum Beraud et Stephanum Michaelem, 1585).

64-Abiçena, de las fuerças del coraçon/ Avicennae libri in Re medica omnes, qui hactenus ad nos pervenere id est libri Canonis quinque, De viribus cordis, De removendis nocumentis in regimine sanitatis, de sirupo acetoso et cautica omnia, a Ioanne Paulio mongio et Ioanne Costaeo recognita (tomus primus-secundus). Venetiis: apud Vincentium Valgrisium, 1564).

65-Joan Ganareo, sobre el salmo De çeli enarrant/ Tal vez Amicus medicorum...cum opusculo quod inscribitur Caeli enarrant. ..quibus adiecimus astrologiam Hippocratis. Lugduni: apud Guilielmum Rovilium, 1550.

66-Dioscorides, de la propiedad de las yervas/ Historia de las yerbas y plantas, sacadas de Dioscorides Anazarbeo y otros insignes autores, traduzida nuevamente en español por Juan Jarava...Anvers: en la gallina gorda, por Arnaldo Byrman, 1557 (en casa de Juan Lacio).

67-Pedro Alçiomo, sobre Aristoteles de ystoria animalia/ In hoc volumine haec continentur: Aristotelis De historia animalium libri IX...de communi animalium motu liber I, Petro Alcyonio interprete...indices in prefatorum operum singula. Parisiis: ex officina Simonis Colinaei, 1524, 1523.

68-La naturaleza de las yervas, Joane Ruelio en un libro/ De natura stirpium libri tres, Ioanne Ruellio authore cum indice. Basileae: in officina Frobeniana, 1537 y edics. post. en 1543.

Hispania Sacra, LX

121, enero-junio 2008, 143-171, ISSN: 0018-215-X 
69-Pauleo Ginetto sobre mediçina/ Pauli Aeginatae, De medica materia libri septem...quinque Albano Torino interprete, sextus...Ioanne Bernardo Feliciano...Venetiis: in aedibus Lucaeantonii Iuntae florentini, 1532.

70-Argentorato, de la demostracion de yerbas/ Tal vez Pedacii Dioscoridae pharmacorum simplicium reique medicae libri VII, Ioanne Ruellio interprete, una cum Hermolai Barbari corollariis et Marcii Vergilii, in singula capita censuris sive annotationibus. In inclyta Argentorato: apud Ioane Schorrum, 1529.

71-La obras de Ipocrates/ Tal vez los Aforismo de Hipocrates (diversas edics. en ciudades europeas).

72-Las obras de Jeronimo Bonbilo sobre los Aforismos de Ipocrates/

73-Plinio, de Natural Historia/ Tal vez Caii Plinii Secundi, opus divinum titulus Historia Naturalis...cum annotationibus Hermolai Barbari. Varias edics. en diversas ciudades europeas.

74-Las quatro partes de Santo Tomas/ Summa Sacrae Theologiae...in quatuor tomis contentis divisa Divi Thoma Aquinate...Thomae a Vio Caietani commentariis illustrata. Lugduni: sumptibus Philippi Tinghi, 1575.

75-Compendio de todas las Sentencias de Santo Tomas/ Tabula seu index atque compendium et epilogus Omnium Sententiarum Divi Thomae Aquinatis per conclusiones resolutas, quae in omnibus libris vel commentariis eiusdem diffusii continentur atque tractantur... a Pedro Bergomensi coactum...Venetiis: apud haeredes Lucaeantonii Iuntae, 1539.

76-Santo Tomas sobre las Epistolas/ Commentariorum divi Thomae super Pauli Epistolae labore Jacobi Castrensis...Lugduni: apud Sebastianum Barthol, 1556.

77-Santo Tomas contra los Gentiles/ Summa contra Gentiles divi Thomae Aquinatis, ex Praedicatoria familia, quatuor libris comprehensa commentariis, Francisci de Sylvestris...ordinis item Praedicatorii, Ferrariensis doctoris Theologi diligenter et accuratae repurgata. Varias edics. en Amberes, París a mediados del s. XVI.

78-La Catena aurea de Santo Tomas/ Catena aurea angelici Thomae Aquinatis in evangelium Matthaeum, Marcum, Lucam et Ioannem...Edics. en Lyon en 1520, en Roma en 1570.

79-Alberto Magno sobre las Sentencias/ Scriptum in quattuor libros Sententiarum., Basileae: Jacobus Wolff, 1506.

80-Durando/ Rational Divinorum Officiorum a R. Guilielmo Durando Mimatensi episcopo...concinatam. Lugduni: apud haeredes Iacobi Iuntae, 1560, y edics. post. en Amberes, Venecia, etc.

81-Pedro Lombardo, sobre el maestro de las Sentencias/ Impreciso (comentarios de Sto. Romás de Aquino, de Dionisio el Cartujano). 
82- Alegorias sobre el Testamento viejo y nuevo.

83-La historia de fray Francisco Ximeniz/ Tal vez De rebus gestis a Francisco Ximenio Cisnerio...libri octo, Alvaro Gomecio authore. Compluti: apud Andream de Angulo, 1569.

84-Thesauro de predicadores, sobre la forma de predicar/ Tal vez Libro llamado thesoro de angeles, compuesto por el padre fray Francisco de Evia, predicador de la Orden de los flayres (sic) menores de Sant Francisco...en el qual se contienen cosas muy notables y muy provechosas assi para predicadores como para confessores. Astorga: Agustin de Paz, 1547.

85-Las Constituciones sinodales del obispado de Pamplona/ Tal vez se refiera al Sínodo Diocesano de 1576-77, que no se llegó a imprimir, pero del que hay datos en el Archivo Catedralicio de Pamplona/ O los Statuta seu Constitutiones synodales...domini D. Alexandri...episcopi Pampilonensis...promulgate et publicate die quindecime mensis Decembris, Millesimo quingentesimo trigesimo primo. Impresse Lugduni: per Dionysium Harsy, 1532.

86-Las obras de Fulgencio Afro y de Magencio Juan/ Opera divi Fulgentii Afri episcopi Rupensis, librorum multorum accessiones...locupletata. Antuerpiae: apud Christophorum Plantinum, 1574 (Lovanii excudebat Ioannes Masius, 1572).

87-Sermones de San Leon Papa/ I divini sermoni di San Leon Papa, tradotti di latina in volgare per Gabriel Foresto da Brescia. Venetia: al segno de la Speranza, 1547.

88-San Gregorio sobre la Predestinacion/ De libero arbitrio et meritis bonorum operum assertio catholici ad Gregorium XII Pontifice maximo, authore Rmo. P.F.C. de Capita Fontium, totius ordinis Minorum generali ministro. Antuerpiae: ex oficina Christophori Plantini, 1575.

89-Las obras de San Eusebio obispo de Cessario/ Eusebii Pamphili Caesariensis...opera...Basileae: per Henricum Petri, varias edics. desde 1542, y también en París: apud Michaelem Somnium, 1581.

90-Diçionario de Calepino/ Ambrosii Calepini Dictionarum. La edición más completa con términos sobre diez lenguas, (decem linguarum: latinis, hebreae, graecae, gallicae, italicae, germanicae, hispaniae, polonicae, ungaricae atque anglicae). Varias edics. en Venecia, Lyon.

91-Adagios de Erasmo / Erasmi Roterodami...Adagiorum chiliadas tres ac centuriae fere totidem. Basileae: in aedibus Ioannis Frobeni, 1513 o edics. post.

92-Las obras de Clemente Alexandrino/ Clementis Alexandrini, omnia quae extant opera...Gentiano Herveto interprete. Parisiis: apud Guilielmum Iulianum, 1590. 
93-Las obras de Seneca/ L. Annaei Senecae opera quae extant omnia (las hay comentadas por Erasmo de Roterdam, Celio Secundo Curion, Antonio Mureto, el Pinciano, etc). Varias edics. en diversas ciudades europeas.

94-Las obras de Pico Mirandulo en un cuerpo/ Tal vez Opera omnia Ioannis Pici Mirandulae sunt autem haec quae ab hoc autore..scripta. Basilea: per Heinricum Petri, 1557.

95-Las obras de Nicolas Orio/

96-Las Tragedias de Seneca/ Tragediae Senecae cum duobus commentariis Bernardinus Marmita, Daniel Gaietanus.Venecia: Philippo Pincio Mantuano, 1510 .

97-Joanes Chlobeo sobre las Sentencias/ Tal vez Ioannis Stobaei Sententiae ex thesauris graecorum collectae...per Conradum Gesnerum latinitati donatae. Edics. en diversas ciudades europeas.

98-Marsilio, sobre el primero de las Sentencias/ Marsilii Ficinii florentini...Opera et quae hactenus extitere...in duos tomos digesta ...una cum gnomologici, hoc est Sententiarum ex iisdem operibus collectarum...Basileae: ex officina Henricpetrina, 1531 o edic. post. de 1576.

99-Suma Silvestrina/ Silvetrina Summa summarumque quae Silvestrina nuncupata edita ab...Silvestro Prierate. Varis edics. en Lyon desde 1521.

100-Almain sobre los morales y otros muchos tratados/ Tal vez Moralia acutissimi et clarissimi doctoris...Iacobi Almain...cum eiusdem Iacobi et David Cramston Scoti additionibus. Varias edics. en París ${ }^{35}$.

101- Las obras de Guillermo Altisiberensi en dos cuerpos/ Tal vez Guillermo Altisidorense (d'Auxerre), Summa aurea in quattuor libros Sententiarum. París: Philippus Pigouchet, impensis Nicolai Vaultier et Durandi Garlier, 1500.

102-Alexandro de Alos sobre las Colaçiones/ Tal vez Selectae similitudines sive collationes tum ex Bibliis sacris, tum ex Veterum orthodoxorum commentariis, per Alardum Amstelradanum, tomis tribus concinatae. Diversas edics. en ciudades europeas.

103-Bergilio/ Impreciso, sobre la obra de Publio Virgilio Marón.

104-Luys Bibes sobre las Disciplinas/ Ioannis Ludovici Vivis, De disciplinis liber XX. Antuerpiae: Michael Hielenium, 1531 (y edics. post. en Colonia, Lyon).

35 Jacobo Almain, comenzó a estudiar en el reformado Colegio de Monteagudo de la universidad parisina, para Licenciarse en Teología por el Colegio de Navarra. Destacó en el terreno de la Teología práctica escribiendo diversos libros sobre Moral que tuvieron gran influencia (Vid. R. GARCía VILLOSLADA, La universidad de París...pp. 165-168. 
105-Petro Ramo sobre Ciceron, de Sono Cipionis/ Scipionis Somnium ex sexto M.T. Ciceronis, De Republica, Petri Rami praelectionibus explicatum. Parisiis: ex typographia Mttahaei Davidis, 1550.

106-La Istoria de Tito Libeo en tres cuerpos (sic)/ Tal vez Titi Livii Patavini, Decadis, liber primus-tertius. Compluti: excudebat Ioannem Mey Flandros, prostant exemplaria apud Bartholomeum a Robles (s.a.).

107-Las Anotaciones de Bodeo (sic)/ Tal vez Annotationes Guilielmi Budaei...in quatuor et viginti Pandectarum libros...Parisiis: apud Iodoco Badio Ascensio impressae, 1532 (o edics. post) ${ }^{36}$.

108-Las obras de Beroso/ Tal vez La antichita di Beroso Caldeo...et d'altri scrittori cosi hebrei como greci et latini che tratano delle stesse materie, tradotte, dicharate et con diverse utili et necessarie annotationi illustrate, da M. Francesco Sanssovino. Vinegia: preso Altobello Saliceto, alla libraria della Fortezza, 1583.

109-Las obras de Omero en griego y latin/ Commentarius explicationis primi libri Iliadas Homeri, Ioachimi Camerarii Pabergensis eiusdem libri, primi Iliadas conversio in latino versus eodem autore. His graeca etiam adiecta sunt. Argentorati: ex officina Cratonis Anglii, 1538.

110-Oratio cum commento/ Q. Horaii Flacci opera, cum quatuor commentarius, Aeronis Porphyrionis, Antoniii Mancivelli, Iodoci Badii, cumque adnotationibus Matthaei Bonfinis et Aldi Manutii a Philosofo recognitur. Varias edics. en París desde 1519.

111-Enrrico Loriti Glareano, sobre Tito Libero (sic)/ Henrici Glareani, in Titum Livium annotationes, cum chronologia eiusdem, cui Badii accessit elenchus; ad haec Laur. Vallae de quibusdam apud Livium locis iudicium. Lugduni: apud Seb. Gryphium, 1542.

112-Las anotaciones sobre Caietano, de fray Ambrosio Caietano (sic)/ F. Ambrosii Catharini..., ordine Praedicatorum, Annotationes in Commentaria Caietani, denuo multo locupletiones et castigationes reddita. Lugduni: apud Mathiam Bonhomme, 1542.

113-Alexander ab Alexandro/ Alexandri ab Alexandro, Genialium dierum libri sex, nunc postremum infinitis mendis. Parisiis: apud Nicolaum Chesneau, 1575.

114-Nicolao Xerbelio, sobre la Descrepçion de Grecia/ (existe una descripción de Grecia de Pausanias).

\footnotetext{
${ }^{36}$ Guillermo Budeo, jurista y humanista que llegó a ser secretario de Luis XII de Francia, falleciendo en 1540. Aprendió griego con Lascaris llegando a ser uno de los más profundos helenistas de la epoca. (Vid. R. García Villoslada, La universidad de París... p. 330.

Hispania Sacra, LX

121, enero-junio 2008, 143-171, ISSN: 0018-215-X
} 
115-Las obras de Luciano Samosatense/ Luciani Samosatensis opera, quae quidem extant omnia, e Graeco sermone in latinum conversa; nunc postremum multo diligentius et melius quam ante ad graecum exemplum correcta et emendata. Varias edics. en París, Lyon, Franckfurt.

116-Las obras de Marco Antonio Sabelico en dos cuerpos/ M. Antonii Cocii Sabellici, Opera omnia ad infinitis...mendicis repurgata et castigata; cum supplemento Rapsodiae historiarum ab Orbe condito; atque haec omnia per Caelium Secundum Curionem...confecta...in tomo quatuor digesta. Basileae. Per Ioannem Hervagium, 1560.

117-Suetonio Tranquilo/ Vida de los doce Cesares, Cayo Suetonio Tranquilo. Madrid: s.n, 1579.

118-Las obras de Omero en griego/ Tal vez Homeri Ilias et Odyssea (Odyssea, Batrechocia, Hymni et Epigramata). Ginebra: I. Krispino, 1570.

119-Climentos Alexandrino/ Clementis Alexandrini...Omnia quae quidem extant opera...Gentiano Hervato Aureliano interprete. Varias edics. en París, Basilea, Heidelberg.

En griego

120- Arte griega/ Tal vez se trate de la obra de Juan Reuchlin, autor de la primera gramática griega escrita por un cristiano en $1506^{37}$.

121-Las obras de Platon con los comentos de Proclin Timeo/ Apanta Platonos meth'ypomnemmaton Proklon eis ton Timaion kai ta Politika=Platonis omnia opera, cum commentariis Procli in Timaeon et Politica. Basilea: Apud Io. Valderum, 1534.

122-Los Dialogos de Theodoritio obispo de Çiria/ Beati Theodoreti episcopi Cyri Eranistes seu Polymorphus, in quo tribus dialogos contra quosdam sui temporis haereticos acerrime et subtilissime disputat. ..Basileae: s.n, s. a, (per Iacobum Parvum, sumptibus Ioannis Oporini, 1549).

123-Diccionario griego/ Tal vez Tà tón lexicon éllenikon semantiká katá stoicheîon. Basileae: per Hienonymum Curionem, 1543.

124-Las Comedias de Aristofenes(sic) en griego/ Aristophanous eutrepelotaton Komodiae hendika=Aristofanis gautissimi Comoediae undecim: comoediarum catalogum versa pagella indicabit. Parisiis. apud Chrstianum Wechelum, 1540 .

${ }^{37}$ L. SagalÉs Sisquella, La hermenéutica...p. 80. 
125-La Iliada de Omero y Odiseo, con diferentes interpretes/ Hommerou Illias kai Odyssea=Homeri Ilias et Ulyssea cum interpretationes. Basileae: apud Io. Hervagium, 1535.

126-Eustaquio sobre las obras de Omero/ Eustathion archepiskopou Thessalonikes, parekbolai eis tou Homerou Illiada kai Odysseian meta euporotaton kai pan ophelimou pinakos. Romae: apud Antonium Bladum, 1542(1550).

127-Repite nota 125.

128-Pratica de Balisio sobre Medeçina/ Tal vez Omnia D. Basilii Magni opera...Iano Cornario medio physico interprete. Basilea: ex officina Frobeniana, apud Hieronymum Frobenium et Nicolaum Episcopium, 1540.

129-Los commentarios de Budeo sobre la lengoa griega/ Commentarii linguae graecae Guilielmo Budaeo...auctore. Parisiis: ex chalcographia Iod. Badii Ascens, 1529, y edics. post. en Colonia, Basilea, Venecia.

130-Aristoteles en griego, en dos cuerpos en tabla enquadernados/ Debía ser parecido a Aristoteloys Sozomena=Operum Aristotelis (tomus primus-secundus). Genevae: apud Guillielmum Laemarium (en edic. de 1591 (1590).

131-Instituciones del derecho çivil de Theofilo/ Institoutiones Theophilon Antikensoros=Institutiones iuris civilis in graecam linguam per Theophilum Anticensorem traductae. Lovanii: ex officina Rutgeri Rescii, 1536. Otras edics. en París, Basilea, Génova.

132-Obras de Theofilo de la impresión de Roma/

133-Eusebio Panfilo/ Tal vez Eusebio Panfilo. Contra Hieroclem quae Tynaeum, Christo conferre conatus fuerit. Venetiis: in aedibus Aldi Manucii, 1502.

134-Ecclesistica Historia de Eusebio en griego/ Eusesbiou tou Pamphilou Ecclésiastiké Historia=Eusebii Pamphili Ecclesiasticae Historiae libri decem... (aunque la versión que hemos encontrado es de fines del XVI, editada en París por Pedro Petit).

135-Las obras de Clabio (sic) Joseph en griego/ Phlabiou Iosephou Ioudaikes archaiologuias logoi kai aloseos logoi z. peri archaiotatos Ioudaion kata Apionos logoi b. Eis tous Makkabaious logos e peri autokratoras logismou. Basileae: per I. Frobenio kai N. to Episkopo, 1544.

136-El tratado de los libella de Rofredo beneventano/ Dn. Rofredi Beneventani....tractatus, in quo ordinis iudiciarii positiones libellique pertractantur, opus praeterea Libellorum in ius Pontificum atque XLIIII. Sabattinae quaestiones nunc recens addita. Lugduni: apud haeredes Iacobi Iuntae, 1561.

137-El Testamento viejo en ebreo en seis tomos/ Hay una Biblia rabínica impresa en Venecia en 1517. 
138-Dos diccionarios ebreos/ Tal vez Ootser ha-jeleg rishon ha-mikol= Compendium Michlol, hoc est absolutiss. Grammatices Davidis chimhi, nuc primo editum, autore Rodolpho Bayoro. Parisiis: apud Carolum Stephanum, 1554/ O Dictionarium hebraicum novum...autore Ioanne Forstero. Baileae: per Frobenium et Episcopum, 1564.

139-Dos Decretos, el uno de cuerpo grande, el otro pequeño/

140-El Sexto de las Decretales y las Clementinas/ Tal vez Casus longi super sexto libro Decretalium et super Clementinis (edic. incunable en París, Lyon, Estrasburgo).

141-En pequeño volumen seis cuerpos de Decretales solo el texto.

142-El Codigo de Justiniano/ Codicis D. Justiniani...lib. XII. Lugduni: apud Guilielmum Rovilium, 1581.

143-Colect. sobre las Sentencias/ Tal vez Isagoge ad scansionem carminum alias corrupte emissa in lucem nunc emendatissimae impressae...Collectanea Sententiarum Severini Boetii, Collectanea Sententiarum Valerii Martialis, Collectanea Sententiarum Ioannis Cantalycii, Collectanea Sententiarum ex libris Ovidii Nasonis. Impresum Taurini: per Nicolaum Benedictum et Antonium Ranotum, 1518.

144-Guillermo de Ocaian sobre las Sentencias / Guillermo de Ockam, impreciso.

145-Las Tablas de Tholomeo/ Geographiae Cl. Ptolomaei a plurimus viris utriusque lingua doctissime emendata, et cum archetypo graeco ab ipsis collata...correcta a Marco Beneventano et Ioanne Cotta Veronensis, tabula Io. a Ruysch germano elaborata. Roma: expensis Evangelista Rosino Brixiano, 1508 (Impresum per Bernardinum Venetum de Vitalibus, 1507).

146-Origenes sobre el Testamento viejo/ Tal vez Origenes super Genesim, Exodum, Leviticum, Numeros, Iesum ... et libros Iudicum, divo Hieronymo interprete. Venetiis: in aedibus Aldi Ro. 1503.

147-Las obras de Joanes major Escoto/ Ioannis Duns Scoti, Ordinis Minorum (impreciso).

148-Dialogos del maestro Guillermo Ocan/ Guillermo Ockam.

149-Sobre el profeta Ezechiel en pergamino/ Probablemente manuscrita. En versión impresa, hay ediciones de F. Hectoris Pinti lusitani Hieronymiani, In Ezechielem prophetam commentaria, en varias ciudades europeas.

150-De los echos romanos en pergamino/Probablemente versión manuscrita de la obra de Valerio Máximo, de la que hay diversia edics. impresas entre ellas Valerio Maximo noble philosopho y orador romano, coronista de los notables dichos y hechos de los romanos y griegos, traducido por mosen Ugo de Urries. 
Impresso en la universidad de Alcala de Henares: en casa de Miguel de Eguia, 1529.

151-Colaciones de los Santos en pergamino/ Tal vez Vigintiquatuor collationes sanctorum Patrum conscripte, ab Ioanne eremita qui et Cassianus dicitur. Lugduni: Iacobus Myt, 1525.

152-Un libro antigo de interpretaçiones de bocablos.

153-Aurelio Agustino en impresion antigua/ Tal vez Index omnium quae insigniter a D. Aurelio Agustino dicta sunt.

154-Las obras de Jeronimo Pardo sobre la Dialetica/ Medulla Dyalectices edita a perspicacissimo Artium preceptore Hieronymo Pardo, de novo correcta et emendata cum tabula...per magistrum Iohannem Maioris...necnon per Jacobum Ortiz. Parisius: apud Guillelmum Anabat (impensis Durandi Gerlieri, 1505).

155-El maestro Petri Tareto/ Pedro Tatarero (impreciso).

156-Los posteriores de Pedro de Aliaco/ Tal vez Opusculum de Sphera Mundi de Sacrobusto, cum additionibus et familiarissimo commentario Petri Cirueli Darocensis, nunc recenter correctis ...intersectis etiam egregiis questionibus domni Petri de Aliaco. In alma Complutensi universitate: apud Michaelem de Eguia, 1527.

157-Las obras de Ciceron en impresión antigua/ Impreciso.

158-Libro escrito de mano en papel en lengua castellana, de la materia angelica/ Tal vez de la obra de Francesc Eiximenis, De natura angelica.

159-Solino, De las maravillas de mundo/ Solinus, De memorabilibus Mundi diligenter annotatus Cayo Iulio. Paris: Iodoco Badio, hacia 1503, y otras edics. post..

160-La retorica de Ciceron con muchas comentadores/ Tal vez En habes lector in omnes de Arte Rhetorica M. Tulii Ciceronis libros, doctissimorum virorum commentaria. Basileae: ex officina Roberti Winter et Thomae Platteri, 1541.

161-Las elegancias de Lorençio Bala/ Laurentii Valle, De lingua latina quam optime meriti elegantiae una cum additionibus assuetis, recenter impressa et adamussim correctae. Parisius: venudantur a Iohanne Petit, 1509.

162-Sobre los Morales de Aristoteles Eustraçio y otros/ Aristotelis Stagiritae Moralia Nichomachia, cum Eustratii Aspasii, Michaelis Ephesii explanationibus...nuper a Ioanne Bernardo Feliciano latinitate donata. Parisiis: apud Ioannem Roigny, 1543.

163-Todas las obras de Ciceron en dos cuerpos enquadernadas en tablas/

164-Las Instituciones oratorias de Quintiliano/ M. Fabii Quintiliani...De institutione oratoria libri duodecim/Varias edics. en Venecia, Paris, Lyon, etc. 
165-Las observaciones sobre las obras de Ciçeron/ Marii Nizolii Brixellensis in M. T. Ciceronem Observationes utilissimae. Varias edics. en Lyon, Venecia, Basilea.

Y toda la dicha librería queda en el dicho monesterio en poder del dicho reverendisimo señor Dn. Fray Martin Xuarez abbad, y se dio por entregado della a su voluntad. De cuya real entrega doy fee yo el escribano, y lo asente por auto, estando presentes por testigos Martin de Larrasoaña y Miguel de Collantes, estantes en el dicho monasterio. Y firmaron el dicho señor abbad y comisario.

Martin Xuarez (rúbrica), El licenciado Daoiz (rúbrica). Passo ante mi Miguel de Irigoyen (rúbrica). 